\title{
New paradigms in the pathogenesis of otitis media in children
}

\author{
James Mark Coticchia ${ }^{1}{ }^{*}$, Michael Chen ${ }^{1}$, Livjot Sachdeva ${ }^{1}$ and Sean Mutchnick ${ }^{2}$ \\ 1 Department of Otolaryngology - Head and Neck Surgery, Wayne State University School of Medicine, Detroit, MI, USA \\ ${ }^{2}$ Wayne State University School of Medicine, Detroit, MI, USA
}

\section{Edited by:}

Lokesh Guglani, Children's Hospital of

Michigan, USA

Reviewed by:

Rajeev Bhatia, Akron Children's

Hospital, USA

Deepak Kumar Mehta, Children's

Hospital of Pittsburgh, USA

${ }^{*}$ Correspondence:

James Mark Coticchia, Department of

Otolaryngology - Head and Neck

Surgery, Wayne State University

School of Medicine, 4201 St. Antoine,

5E UHC, Detroit, MI 48201, USA

e-mail: jcoticch@med.wayne.edu
Acute otitis media (AOM) is a multifactorial disease with a significant socioeconomic impact. The pathogenesis of AOM is attributed to a variety of well-established internal and extrinsic factors. Recent evidence strongly points to bacterial biofilm formation as an important contributor to this disease entity. The nasopharynx is a likely reservoir for infection with subsequent seeding of pathogens to the middle ear via planktonic shedding. Various modalities have been used to directly detect biofilm formation in the middle ear mucosa of children with AOM. Further insights into this disease may lead to new strategies for prevention and treatment.

Keywords: otitis media, otitis media with effusion, acute otitis media, biofilms, pathogenesis, middle ear infection

\section{INTRODUCTION AND EPIDEMIOLOGY}

\section{PREVALENCE AND SOCIOECONOMIC IMPACT}

Otitis media (OM) is one of the most common childhood infections. Clinically it is characterized by middle ear effusion (MEE) and recognized as acute otitis media (AOM) or OM with effusion (OME) $(1,2)$. OM is the leading reason for visiting the doctor, prescribing antibiotics, and undergoing surgical procedures among children (1,3-6).

The peak incidence of AOM is between 6 and 12 months of age $(7,8)$. More than $80 \%$ of children are diagnosed with AOM by age 3 (7). National medical expenditures for OM have been estimated at approximately $\$ 4.1$ billion for children $(9,10)$. While the incidence of OM in the U.S. rose steadily in the latter part of the twentieth century (8), there has been decline in the number of pediatric office visits between 1997 and 2007 (11). Rates of recurrent AOM (RAOM, defined in the study as $>3$ episodes in the previous 12 months) also declined between 2001 and 2005 (11).

The declining incidence of OM may be attributed to a number of factors that have been the focus of public health and education. The 7-valent pneumococcal conjugate vaccine (PCV7) was introduced in 2000 and has excellent efficacy against invasive pneumococcal disease (12-14). The "watchful waiting" guidelines aim to prevent unnecessary physician consultation for mild OM (14). Reductions in known risk factors such as smoke exposure may further contribute to the decline $(14,15)$.

\section{WIDESPREAD ANTIBIOTIC USE AND INCREASING BACTERIAL RESISTANCE}

Use of broad-spectrum antimicrobials in the United States has increased over the last several decades $(15,16)$ and is directly correlated to rising antibiotic resistance $(17,18)$. Decreasing susceptibility of invasive $S$. pneumonia - the most common cause of pediatric AOM - to penicillin, clindamycin, and macrolides began in the mid-1990s (15, 19-21).

The serotypes covered by PCV7 were selected to protect against strains prominent among children worldwide and strains likely to develop antimicrobial resistance (22). The decrease in prevalence of PCV7-related S. pneumoniae has been met with increasing prevalence of PCV7-unrelated S. pneumoniae $(23,24)$ and $H$. influenzae $(4,25)$.

Selective pressure from the inappropriate use of antimicrobial agents is the single greatest factor influencing the spread of resistant S. pneumoniae and other common middle ear pathogens $(15,18,20,23,25)$. Despite efforts by the Center for Disease Control (CDC) to minimize inappropriate use of antimicrobials, these practices continue to select for resistant pathogens. Strict guidelines for the diagnosis and treatment of $\mathrm{OM}$ are imperative.

\section{DIAGNOSIS, SIGNS, AND SYMPTOMS}

Children may present with non-specific findings such as eartugging, irritability, fever, or symptoms of a viral illness (3). Symptom duration and severity are not reliable indicators of AOM (3, 26). Accurate diagnosis of AOM requires a thorough examination of the tympanic membrane (TM) (3).

Recent updates to the AAP/AAFP guidelines for the diagnosis and treatment of AOM in children have narrowed down the diagnostic criteria, particularly in its distinction from OME (3). Diagnosis requires the presence of MEE with acute onset of signs and symptoms of middle ear inflammation. MEE is established by an air-fluid level behind the TM, impaired TM mobility on pneumatic otoscopy, or otorrhea signifying TM perforation. AOM is reliably distinguished from OME by the addition of a "cloudy" and moderate-to-severe bulging of the TM; less specific signs include significant TM erythema or hemorrhage $(3,27,28)$. Additional 
methods for confirming MEE include tympanometry, acoustic reflectometry, or tympanocentesis.

\section{RISK FACTORS \\ HOST}

AOM is most common in infancy and early childhood, with peak incidence between 6 and 12 months of age $(7,8)$. The immature state of the immune system in young children predisposes them to infection, particularly with encapsulated bacteria (29). Incidence tends to be higher in males $(7,30,31)$.

The etiology and pathogenesis of AOM are multifactorial and represent the interplay between genetic and environmental factors (11). Twin studies have shown that heritability accounts for 74 and $45 \%$ of variation in RAOM incidence in females and males, respectively (29). Several indigenous populations are high-risk for OM: Native Americans, the Alaskan, Canadian and Greenland Inuit, and Australian Aborigines $(11,32)$. Recent availability of genomewide association studies (GWAS) has greatly expanded the ability to search for related genes (30).

The Eustachian tube (ET) helps maintain healthy middle ear conditions. The ET of infants in relation to their fully matured anatomy is of a smaller caliber, shorter length, and joins the nasopharynx at a more acute angle, all of which predispose to dysfunction of the ET and therefore increased risk of infection $(31,33)$. Children with craniofacial anomalies, such as cleft palate and Trisomy 21, are at increased risk of middle ear disease due to further ET compromise (34-37). Histopathology studies have reported deformed ET cartilage (38) and high incidence of OM (36) in patients with cleft palate.

Some studies have postulated that atopic diseases such allergic rhinitis and asthma can play a role in OM (39). This may be due to increased susceptibility to invasive pneumococcal disease. However, the exact causal relationship has yet to be elucidated.

\section{ENVIRONMENT}

Upper respiratory tract infections (URTI), both viral and bacterial, have been implicated in the development of AOM due to mucosal inflammation leading to adenoid hypertrophy, ET dysfunction, and disruption of mucociliary defenses $(31,40,41)$. Virus-mediated inflammatory responses in the middle ear impair host immunity, promote bacterial colonization and inhibit antimicrobial penetration into the middle ear (31, 40). A temporal relationship is consistently observed with $\mathrm{AOM}$ incidence peaking 3-4 days after the onset of URTI symptoms (40).

Exposure to tobacco smoke is well known to adversely affect the respiratory tract. Higher colonization by pathogenic bacteria has been demonstrated in the nasopharyngeal flora of smokers and smoke-exposed children (42). Despite this, studies have not found a consistent link between smoke exposure and AOM incidence $(43,44)$. Potential confounding by socioeconomic status, thought to be inversely correlated with household smoking, often complicates the interpretation of such studies (43).

The protective effect of breastfeeding on OM incidence has been reported by the majority of investigators $(43,45)$. Proposed explanations for these protective effects have included head positioning during feeding, exposure to different microorganisms, improved nutrition and the antibacterial or immunological benefits of breast milk (46).

Exposure to other children, whether at day care or to siblings at home, is a strong risk factor for OM (11, 31, 43, 44, 46-48). Specific predictors include attendance by 2 months of age, attendance $\geq 30 \mathrm{~h}$ /week, and day care groups with $\geq 5$ children and $\geq 2$ children 2 years or younger (46).

\section{CLASSICAL THEORY OF PATHOGENESIS}

Classical theories of OM pathogenesis describe MEE and subsequent infection as direct consequences of ET dysfunction. The ET preserves normal middle ear conditions through three primary functions: clearance of middle ear fluid (MEF), ventilation, and protection from nasopharyngeal reflux $(49,50)$.

The drainage system of the middle ear is eloquently portrayed as an inverted flask by Bluestone et al. with the body of the flask representing the middle ear and the narrow neck representing the ET (51). The mucociliary wave transports middle ear secretions toward the nasopharynx. When a precipitating event, such as viral URTI or allergic rhinitis, triggers nasal mucosal inflammation, obstruction of the tubal orifice leads to fluid stasis. Individuals with narrower and horizontally oriented anatomy, cleft palate, or tensor veli palatini deficiency have impaired drainage and are at higher risk for MEE (51).

In the open state, the ET ventilates the middle ear and equalizes pressure with the nasopharynx. This can be done deliberately with the Valsalva maneuver or palatal elevation via the action of tensor veli palatini. Studies have reported middle ear gas absorption at a constant rate of $1 \mathrm{~mL} / 24 \mathrm{~h}(52,53)$, The hydrops ex vacuo theory, original proposed by Politzer, postulates that continuous negative middle ear pressure causes transudation of fluid from mucosa into the middle ear cavity leading to effusion (54). The hydrops ex vacuo theory has been validated in human studies $(55,56)$ and is widely accepted as a key step in the development of MEE.

The et allows greater physical separation between the nasopharynx and middle ear, isolating the middle ear from infection and offensive material originating from the upper aerodigestive tract. This is believed to play a role in the higher incidence of OM in children, who have smaller and more horizontal ET compared to adults. Higher rates of gastroesophageal reflux, confirmed by detection of pepsin/pepsinogen in MEF, have been reported in children with OME or RAOM compared to otherwise healthy children (57). Pepsinogen in the middle ear has also been identified in the adenoids of children with OME, suggesting nasopharyngeal reflux as the likely mechanism (58). While some prospective studies have reported a possible benefit in OM resolution with antireflux therapy, evidence from large controlled trials is lacking $(57,59)$. There are currently no recommendations for the use of antireflux therapy in treating OM.

\section{THE IMPORTANCE OF BIOFILM PHENOTYPES IN OTITIS MEDIA THE CHINCHILLA MODEL}

The vast majority of animal models of OM have utilized the chinchilla. Giebink cites several factors favoring these animals in the study of middle ear disease: (1) it is the only animal model in which $S$. pneumoniae OM can be induced by inoculation directly 
into the middle ear or nasal cavity, (2) infection rarely spreads outside of the middle ear, (3) the middle ear is easily accessible for inoculation and culture, and (4) OM does not naturally occur in chinchillas (60). Research on chinchilla models, beginning in the 1970s, have contributed to the discovery of potent S. pneumoniae serotypes (61), identify a role for nasopharyngeal viral infection in OM pathogenesis, and confirm an immunogenic response to pneumococcal vaccination (62). Today, the chinchilla model remains the cornerstone of basic science research in OM.

\section{NASOPHARYNGEAL BACTERIAL COLONIZATION}

Nasopharyngeal colonization with potential middle ear pathogens is regarded as the initial event leading to OM in humans $(63,64)$. This theory is strongly supported by work on chinchilla models (65), which have shown a close correlation between nasopharyngeal and middle ear pathogens known to cause AOM (66). At the same time, children without RAOM carry greater species of benign nasopharyngeal flora which are thought to inhibit colonization and proliferation of pathogenic species (67). Many surgeons now routinely obtain middle meatus or nasopharyngeal cultures in children with RAOM to identify the causative agents and guide antimicrobial therapy.

\section{BIOFILMS AND PLANKTONIC SHEDDING}

Biofilms are increasingly recognized as a key component of many chronic and treatment-resistant diseases. Hall-Stoodley et al. define biofilms as "surface-associated microbial communities surrounded by an extracellular polymeric substance matrix" which are notoriously resistant to host immune responses and antimicrobial therapy $(68,69)$. Properties of biofilms favoring their survival include (1) poor antimicrobial penetration, (2) decreased oxygen and nutrient requirements, (3) increased expression of resistance genes (e.g., beta-lactamase), and (4) cell-to-cell signaling via quorum sensing $(70,71)$. The extracellular matrix confers reduced permeability to topical and intravenous antimicrobials and along with other putative resistance mechanisms of biofilms (slower growth rate, oxygen depleted microenvironment, and other environmental stresses due to altered physiologic conditions) accounts for the frequent failure of traditional therapies (70). Quorum sensing involves intercellular transmission of molecules and genetic information which permit coordinated behavior and reaction to the local environment (71). Extensive research efforts to understand the biofilm environment have identified a number of therapeutic targets and will be discussed in the next section.

An overwhelming majority of bacteria in the human body exist in the biofilm state during which they are extremely difficult to culture (72). Bacterial biofilms have been implicated in chronic rhinosinusitis (Staphylococcus aureus) (73), recurrent UTI (E. coli), and cystic fibrosis pneumonia (Pseudomonas aeruginosa) $(68,71)$. It is likely that patients with impaired airway clearance are at higher risk for biofilm formation (71), although differences in structure or behavior are unclear. The observation that RAOM often results in negative MEF cultures and recurs despite appropriate antimicrobial therapy has driven the search for biofilms in the middle ear and nasopharynx (74).

Prior studies using chinchilla models led to direct confirmation of middle ear mucosal biofilms in the setting of OM through scanning electron microscopy $(\operatorname{SEM})(75,76)$, and confocal scanning laser microscopy (CSLM) (76). Biofilms were later confirmed in the middle ear mucosa of children with chronic OM $(77,78)$, and on the surface of tympanostomy tubes extracted from children with RAOM (75) and OME (79). None of these studies identified significant biofilms in healthy controls, strongly suggesting a role for biofilms in RAOM pathogenesis. Hoa et al. reported that within 8 days of nasopharyngeal inoculation with influenza A virus and $S$. pneumonia in chinchillas, $83 \%$ of animals developed nasopharyngeal biofilms, 67\% developed middle ear biofilms, and all animals with middle ear biofilms also had nasopharyngeal biofilms (80). Hoa suggested that the presence of nasopharyngeal biofilms may be a prerequisite for development of biofilms in the middle ear.

Within the nasopharynx, the adenoids are a likely reservoir for pathogenic bacterial biofilms (64, 81-83). Adenoid biofilms may be particularly critical in the pathogenesis of RAOM compared to OME. Zuliani et al. and Hoa et al. demonstrated significantly greater biofilm coverage of adenoid mucosa in children with RAOM compared to children with OME or OSA $(81,82)$.

A unique feature of biofilms is "planktonic shedding" of bacteria from the biofilm surface into the surrounding space, seeding infection to distant parts of the body in a fashion similar to septic emboli $(81,84,85)$. Planktonic shedding is a continuous process which appears to escalate during conditions of physiological stress and starvation, leading Costerton et al. to propose planktonic shedding as a key survival mechanism of bacterial biofilms (84). Common pathogens have been found in nasopharyngeal biofilms and MEEs of children with RAOM (86) and chronic OME (Sheyn et al., unpublished). These findings are consistent with planktonic shedding from the nasopharynx into the middle ear is a likely mechanism for RAOM and OME pathogenesis and may explain the high frequency of negative MEF cultures and frequent recurrence of these diseases.

\section{DETECTION AND TREATMENT OF BIOFILMS}

Commonly used modalities to detect and measure biofilms include CSLM, SEM, fluorescent in situ hybridization (FISH), lectinbinding, and immunohistochemical techniques (75-78, 80, 82, $83,87)$. These methods require an adequate tissue sample, thus restricting the study of middle ear biofilms to animal models and the study of adenoid biofilms to patients undergoing adenoidectomy, while in vivo studies are all but impossible.

Optical coherence tomography (OCT) is an emerging imaging modality which may allow non-invasive, in vivo detection of middle ear biofilms. This technology uses near-infrared laser waves to penetrate tissue to produce live, three-dimensional images (88), in a manner similar to ultrasound. However, the shorter wavelength of near-infrared waves compared to ultrasound waves permits submicrometer resolution. Like ultrasound, OCT is ideal for use in children because it is well-tolerated, causes no tissue injury, and avoids radiation exposure. Notably, the depth of penetration is limited to 1-2 mm due to scattering artifact. OCT has been used to detect retinal disease in multiple sclerosis (89) and age-related macular degeneration (90), yet its clinical applications may extend to a variety of medical fields (91). Nguyen et al recently demonstrated OCT-based in vivo detection of middle ear biofilms in adults with chronic OM (92). In a follow-up study, OCT findings 
were directly correlated with acoustic measurements of the TM in a similar adult population (93). These early studies were limited in sample size and further investigation is ongoing. OCT remains a highly promising non-invasive method of detecting biofilms which may play a role in diagnosing biofilm-related diseases in the middle ear.

Tympanostomy tubes likely alter middle ear flora by providing ventilation and increased oxygen tension. The impact on biofilm behavior is unclear, but may affect detachment rates (94). As a foreign body, tympanostomy tubes promote biofilm growth in the setting of initial infection by acting as a scaffold for bacterial colonization and extracellular matrix formation. Tube material may be an important factor in biofilm development. An in vivo animal study found that among several materials, only ion-bombarded silicone tubes prevented $S$. aureus biofilm adherence (95), although this effect was not seen with $P$. aeruginosa (96). Recently, the protective effect of coated silicone tubes has been investigated in several in vitro studies. MRSA is inhibited by vancomycin-coated tubes (97). P. aeruginosa biofilms are inhibited by polyvinylpyrrolidone (PVP)-coated tubes (98) and piperacillintazobactam coated tubes (99). Silver oxide-coated tubes, which reduce postoperative otorrhea (100), do not seem to resist biofilms $(97,99)$. Further research may lead to culture-directed selection of coated tympanostomy tubes to eradicate OM. The risk of selecting for drug resistant strains through low dose antimicrobial therapy remains a concern.

Middle ear biofilms are not eradicated by commonly prescribed topical antimicrobials (101). Agents that are effective in treating upper respiratory tract biofilms, such as mupirocin and gentian violet (102), are difficult to deliver or potentially ototoxic within the middle ear. Proposed strategies focus on electromechanical and biochemical disruption of biofilm adherence and proliferation.

Pulsed laser therapy has been demonstrated to dislodge middle ear biofilms by generating shockwaves (103). Electromagnetic, ultrasonic, and photo-therapy may enhance antimicrobial delivery or activity in certain applications (104).

Biochemical disruption includes identification of specific molecular targets (87), enhanced drug delivery $(104,105)$, and disruption of quorum sensing (105). Drug carriers such as liposomes (106) and biocompatible polymers (104) may offer a way to bypass the protective extracellular matrix, allowing penetration and controlled delivery of antimicrobials directly into the biofilm.

Quorum sensing is a complex process which allows cell-tocell communication between biofilm bacteria. Extracellular DNA, released by cell autolysis, is a method of genetic exchange and is required for biofilm formation (107). DNase has been studied as a way to destroy this free-floating DNA and thus inhibit quorum sensing (108). Alginate lyase targets a key element of the P. aeruginosa extracellular matrix and disrupts existing biofilms (109). Naturally occurring compounds such as bacterial proteins (110) and tea-tree oil (111) may also possess antibiofilm properties.

Bakaletz described early research on several promising vaccines which have shown good efficacy in preventing $\mathrm{OM}$ as well as in vitro studies demonstrating eradication of existing biofilms (87). The possibility of preventative and therapeutic vaccines to target middle ear biofilms may dramatically change the landscape of AOM.

\section{CONCLUSION - IMPLICATION OF BIOFILM INFECTION IN THE PATHOGENESIS OF OM}

Many of these recent studies have demonstrated that RAOM and COME like many other chronic infections in humans such as chronic tonsillitis, cholesteatoma, chronic rhinosinusitis, cystic fibrosis, catheter infections, and infections in implants such as heart valves may be partially explained by the persistent nature of biofilm phenotypes. By combining the classical theories of the pathogenesis of OM with new insights of the nature of biofilms infections we may be able to develop a more comprehensive understanding of OM. Indeed biofilms help to explain many previously documented observations regarding OM, i.e., MEEs that are culture negative and yet have bacterial RNA identified by PCR, persistence of middle ear infections despite appropriate level of therapeutic antibiotics, and the efficacy of low dose antibiotics in the incidence of RAOM.

Our recent work has evaluated the presence of middle ear pathogens by utilizing Real Time PCR in the MEF and adenoids of children with both RAOM and COME. We found that all MEFs contained middle ear pathogens and that every pathogen identified in the MEF was also identified in the matched adenoid specimens (Sheyn et al., unpublished). Although the N-numbers are small, this work suggests that biofilms may play a role in COME.

The algorithm depicted in Figure 1 combines new concepts of biofilm infections with classical models of pathogenesis of OM. In this paradigm, the initial step in the development of RAOM is the exposure of the nasopharynx to known middle

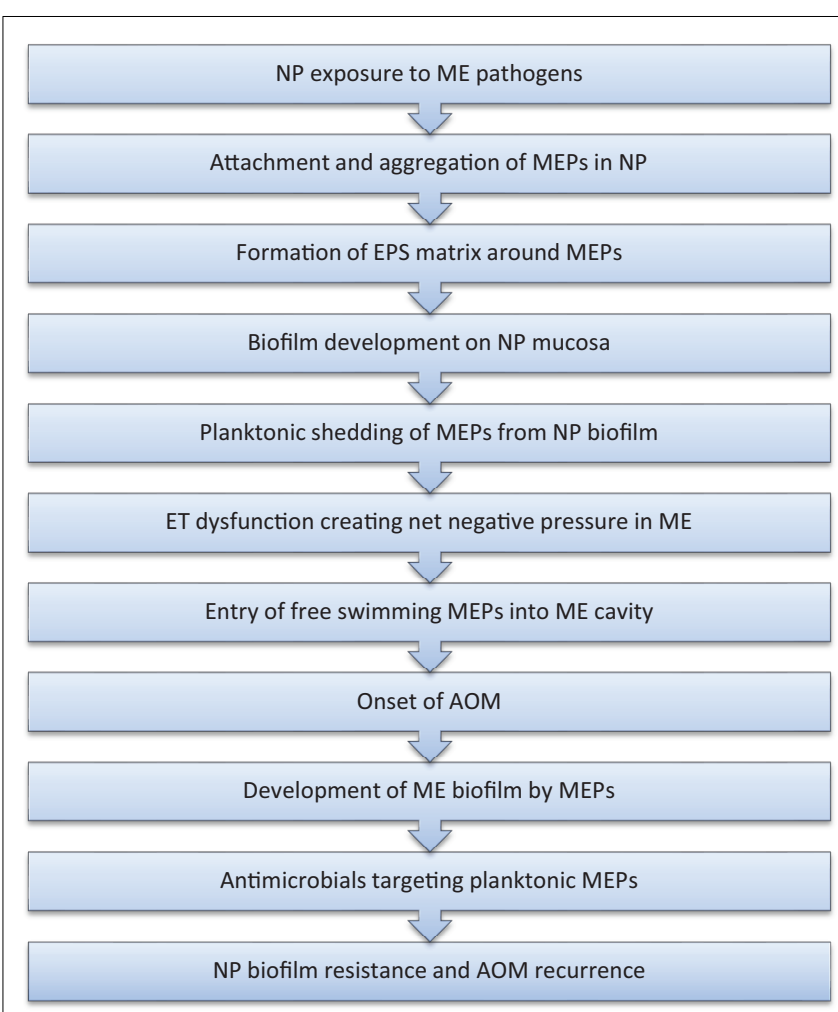

FIGURE 1 | Proposed algorithm for RAOM pathogenesis 
ear pathogens followed by colonization and subsequent biofilm formation by these bacteria. ET dysfunction in otitis prone children creates a net negative pressure in the middle ear and allows planktonically shed middle ear pathogens entry into the middle ear cavity. This is followed colonization and subsequent biofilm formation in the middle ear which results in the development of AOM. This episode of AOM is diagnosed by a primary care practitioner and is usually treated with a short course of antimicrobials. Although the patient may show clinical improvement, presumably due to effective antibiotic treatment of planktonic organisms in the middle ear, the nasopharyngeal biofilm remains resistant and it may again shed planktonic organisms to reinfect the middle ear cavity, resulting in and thus explaining the recurrence of AOM.

Research over the past several decades has elucidated anatomical factors important in the pathogenesis of OM in children. Although there has also been significant research on the identification of common pathogens including $H$. influenzae, S. pneumoniae, and $M$. catarrhalis, the mechanisms these pathogens utilize to colonize and persist in the host have not been well described. Biofilm phenotypes, as previously discussed, have been shown to resist host defenses through several mechanisms and persist despite therapeutic levels of antimicrobials. These characteristics of biofilm infection may help explain recurrent and persistent nature of many infectious entities. Therefore, a more comprehensive understanding of the host-organism via biofilm phenotypes in RAOM and COME expand our knowledge of the underlying pathogenesis of these recurrent and chronic disease states. This information could serve as a springboard in the development of new animal models of OM, new imaging techniques in diagnosis and novel therapeutic interventions for treatment.

\section{REFERENCES}

1. Rovers MM, Schilder AG, Zielhuis GA, Rosenfeld RM. Otitis media. Lancet (2004) 363(9407):465-73. doi:10.1016/S0140-6736(04)15495-0

2. Bluestone C. Definitions, terminology, and classification. In: Rosenfeld RM, Bluestone C, editors. Evidence-Based Otitis Media. Hamilton, ON: BC Decker (1999). p. 85-103.

3. American Academy of Pediatrics Subcommittee on Management of Acute Otitis Media. Diagnosis and management of acute otitis media. Pediatrics (2004) 113(5):1451-65. doi:10.1542/peds.113.5.1451

4. Coker TR, Chan LS, Newberry SJ, Limbos MA, Suttorp MJ, Shekelle PG, et al. Diagnosis, microbial epidemiology, and antibiotic treatment of acute otitis media in children: a systematic review. JAMA (2010) 304(19):2161-9. doi:10.1001/jama.2010.1651

5. McCaig LF, Besser RE, Hughes JM. Trends in antimicrobial prescribing rates for children and adolescents. JAMA (2002) 287(23):3096-102. doi:10.1001/jama. 287.23.3096

6. Arguedas A, Kvaerner K, Liese J, Schilder AG, Pelton SI. Otitis media across nine countries: disease burden and management. Int J Pediatr Otorhinolaryngol (2010) 74(12):1419-24. doi:10.1016/j.ijporl.2010.09.022

7. Teele DW, Klein JO, Rosner B. Epidemiology of otitis media during the first seven years of life in children in greater Boston: a prospective, cohort study. J Infect Dis (1989) 160(1):83-94. doi:10.1093/infdis/160.1.83

8. Hoberman A, Marchant CD, Kaplan SL, Feldman S. Treatment of acute otitis media consensus recommendations. Clin Pediatr (Phila) (2002) 41(6):373-90. doi:10.1177/000992280204100602

9. Bondy J, Berman S, Glazner J, Lezotte D. Direct expenditures related to otitis media diagnoses: extrapolations from a pediatric medicaid cohort. Pediatrics (2000) 105(6):E72. doi:10.1542/peds.105.6.e72
10. Gates GA. Cost-effectiveness considerations in otitis media treatment. Otolaryngol Head Neck Surg (1996) 114(4):525-30. doi:10.1016/S0194-5998(96) 70243-7

11. Daly KA, Hoffman HJ, Kvaerner KJ, Kvestad E, Casselbrant ML, Homoe P, et al. Epidemiology, natural history, and risk factors: panel report from the ninth international research conference on otitis media. Int J Pediatr Otorhinolaryngol (2010) 74(3):231-40. doi:10.1016/j.ijporl.2009.09.006

12. Black S, Shinefield H, Fireman B, Lewis E, Ray P, Hansen JR, et al. Efficacy, safety and immunogenicity of heptavalent pneumococcal conjugate vaccine in children. Northern California Kaiser Permanente Vaccine Study Center Group. Pediatr Infect Dis J (2000) 19(3):187-95. doi:10.1097/00006454-20000300000003

13. Taylor S, Marchisio P, Vergison A, Hausdorff WP, Haggard M. Pneumococcal conjugate vaccines and otitis media. Int J Otolaryngol (2012) 2012:764573. doi:10.1371/journal.pone.0075558

14. Taylor S, Marchisio P, Vergison A, Harriague J, Hausdorff WP, Haggard M. Impact of pneumococcal conjugate vaccination on otitis media: a systematic review. Clin Infect Dis (2012) 54(12):1765-73. doi:10.1093/cid/cis292

15. Hoppe HL, Johnson CE. Otitis media: focus on antimicrobial resistance and new treatment options. Am J Health Syst Pharm (1998) 55(18):1881-97.

16. Coco AS, Horst MA, Gambler AS. Trends in broad-spectrum antibiotic prescribing for children with acute otitis media in the United States, 1998-2004. BMC Pediatr (2009) 9:41. doi:10.1186/1471-2431-9-41

17. Goossens H, Ferech M, Vander Stichele R, Elseviers M. ESAC Project Group. Outpatient antibiotic use in Europe and association with resistance: a crossnational database study. Lancet (2005) 365(9459):579-87. doi:10.1016/S01406736(05)70799-6

18. McCormick AW, Whitney CG, Farley MM, Lynfield R, Harrison LH, Bennett $\mathrm{NM}$, et al. Geographic diversity and temporal trends of antimicrobial resistance in Streptococcus pneumoniae in the United States. Nat Med (2003) 9(4):424-30. doi:10.1038/nm839

19. Tan TQ. Antibiotic resistant infections due to Streptococcus pneumoniae: impact on therapeutic options and clinical outcome. Curr Opin Infect Dis (2003) 16(3):271-7. doi:10.1097/00001432-200306000-00015

20. Mera RM, Miller LA, Daniels JJ, Weil JG, White AR. Increasing prevalence of multidrug-resistant Streptococcus pneumoniae in the United States over a 10year period: Alexander Project. Diagn Microbiol Inf Dis (2005) 51(3):195-200. doi:10.1016/j.diagmicrobio.2004.10.009

21. Jacobs MR, Good CE, Beall B, Bajaksouzian S, Windau AR, Whitney CG. Changes in serotypes and antimicrobial susceptibility of invasive Streptococcus pneumoniae strains in Cleveland: a quarter century of experience. J Clin Microbiol (2008) 46(3):982-90. doi:10.1128/JCM.02321-07

22. Joloba ML, Windau A, Bajaksouzian S, Appelbaum PC, Hausdorff WP, Jacobs MR. Pneumococcal conjugate vaccine serotypes of Streptococcus pneumoniae isolates and the antimicrobial susceptibility of such isolates in children with otitis media. Clin Infect Dis (2001) 33(9):1489-94. doi:10.1086/323027

23. CDC. Office-related antibiotic prescribing for persons aged $\leq 14$ years - United States, 1993-1994 to 2007-2008. MMWR Morb Mortal Wkly Rep (2011) 60(34):1153-6.

24. Farrell DJ, Klugman KP, Pichichero M. Increased antimicrobial resistance among nonvaccine serotypes of Streptococcus pneumoniae in the pediatric population after the introduction of 7-valent pneumococcal vaccine in the United States. Pediatr Infect Dis J (2007) 26(2):123-8. doi:10.1097/01.inf.0000253059. 84602.c3

25. Vergison A. Microbiology of otitis media: a moving target. Vaccine (2008) 26(Suppl 7):G5-10. doi:10.1016/j.vaccine.2008.11.006

26. Laine MK, Tähtinen PA, Ruuskanen O, Huovinen P, Ruohola A. Symptoms or symptom-based scores cannot predict acute otitis media at otitis-prone age. Pediatrics (2010) 125(5):e1154-61. doi:10.1542/peds.2009-2689

27. Lieberthal AS, Carroll AE, Chonmaitree T, Ganiats TG, Hoberman A, Jackson MA, et al. The diagnosis and management of acute otitis media. Pediatrics (2013) 131(3):e964-99. doi:10.1542/peds.2012-3488

28. Shaikh N, Hoberman A, Kaleida PH, Rockette HE, Kurs-Lasky M, Hoover H, et al. Otoscopic signs of otitis media. Pediatr Infect Dis J (2011) 30(10):822-6. doi:10.1097/INF.0b013e31822e6637

29. Kvaerner KJ, Tambs K, Harris JR, Magnus P. Distribution and heritability of recurrent ear infections. Ann Otol Rhinol Laryngol (1997) 106(8): $624-32$. 
30. Rye MS, Warrington NM, Scaman ES, Vijaysekaran S, Coates HL, Anderson $\mathrm{D}$, et al. Genome-wide association study to identify the genetic determinants of otitis media susceptibility in childhood. PLoS One (2012) 7(10):e48215. doi:10.1371/journal.pone.0048215

31. Corbeel L. What is new in otitis media? Eur J Pediatr (2007) 166(6):511-9. doi:10.1007/s00431-007-0461-8

32. Bluestone CD. Epidemiology and pathogenesis of chronic suppurative otitis media: implications for prevention and treatment. Int J Pediatr Otorhinolaryngol (1998) 42(3):207-23. doi:10.1016/S0165-5876(97)00147-X

33. Revai K, Dobbs LA, Nair S, Patel JA, Grady JJ, Chonmaitree J. Incidence of acute otitis media and sinusitis complicating upper respiratory tract infection: the effect of age. Pediatrics (2007) 119(6):e1408-12. doi:10.1542/peds.20062881

34. Malik V, Verma RU, Joshi V, Sheehan PZ. An evidence-based approach to the 12min consultation for a child with Down's syndrome. Clin Otolaryngol (2012) 37(4):291-6. doi:10.1111/j.1749-4486.2012.02482.x

35. Sheahan P, Miller I, Sheahan JN, Earley MJ, Blayney AW. Incidence and outcome of middle ear disease in cleft lip and/or cleft palate. Int J Pediatr Otorhinolaryngol (2003) 67(7):785-93. doi:10.1016/S0165-5876(03)00098-3

36. Kitajiri M, Sando I, Hashida Y, Doyle WJ. Histopathology of otitis media in infants with cleft and high-arched palates. Ann Otol Rhinol Laryngol (1985) 94(1 Pt 1):44-50.

37. Aniansson G, Svensson H, Becker M, Ingvarsson L. Otitis media and feeding with breast milk of children with cleft palate. Scand J Plast Reconstr Surg Hand Surg (2002) 36(1):9-15. doi:10.1080/028443102753478318

38. Sando I, Takahashi H. Otitis media in association with various congenital diseases. Preliminary study. Ann Otol Rhinol Laryngol Suppl (1990) 148: 13-6.

39. Skoner AR, Skoner KR, Skoner DP. Allergic rhinitis, histamine and otitis media. Allergy Asthma Proc (2009) 30(5):470-81. doi:10.2500/aap.2009.30.3272

40. Heikkinen T, Chonmaitree T. Importance of respiratory viruses in acute otitis media. Clin Microbiol Rev (2003) 16(2):230-41. doi:10.1128/CMR.16.2.230241.2003

41. Kleemola M, Nokso-Koivisto J, Herva E, Syrjänen R, Lahdenkari M, Kilpi T, et al. Is there any specific association between respiratory viruses and bacteria in acute otitis media of young children? J Infect (2006) 52(3):181-7. doi:10.1016/j.jinf.2005.05.012

42. Brook I. Effects of exposure to smoking on the microbial flora of children and their parents. Int J Pediatr Otorhinolaryngol (2010) 74(5):447-50. doi:10.1016/j.ijporl.2010.01.006

43. Paradise JL, Rockette HE, Colborn DK, Bernard BS, Smith CG, Kurs-Lasky $\mathrm{M}$, et al. Otitis media in 2253 Pittsburgh-area infants: prevalence and risk factors during the first two years of life. Pediatrics (1997) 99(3):318-33. doi:10.1542/peds.99.3.318

44. Daly KA, Brown JE, Lindgren BR, Meland MH, Le CT, Giebink GS. Epidemiology of otitis media onset by six months of age. Pediatrics (1999) 103(6 Pt 1):1158-66. doi:10.1542/peds.103.6.1158

45. Froom J, Culpepper L, Green LA, de Melker RA, Grob P, Heeren T, et al. A crossnational study of acute otitis media: risk factors, severity, and treatment at initial visit. Report from the International Primary Care Network (IPCN) and the Ambulatory Sentinel Practice Network (ASPN). J Am Board Fam Pract (2001) 14(6):406-17.

46. Ladomenou F, Kafatos A, Tselentis Y, Galanakis E. Predisposing factors for acute otitis media in infancy. J Infect (2010) 61(1):49-53. doi:10.1016/j.jinf. 2010.03.034

47. Rovers MM, Zielhuis GA, Ingels K, van der Wilt GJ. Day-care and otitis media in young children: a critical overview. Eur J Pediatr (1999) 159(1): $1-6$.

48. Macintyre EA, Karr CJ, Koehoorn M, Demers P, Tamburic L, Lencar C, et al. Otitis media incidence and risk factors in a population-based birth cohort. Paediatr Child Health (2010) 15(7):437-42.

49. Bluestone CD, Klein JO. Otitis media with effusion, atelectasis, and Eustachian tube dysfunction. In: Bluestone CD, Stool SE, editors. Pediatric Otolaryngology. Philadelphia: Saunders (1983). p. 356-512.

50. Bylander-Groth A, Stenström C. Eustachian tube function and otitis media in children. Ear Nose Throat J (1998) 77(9):762-4.

51. Bluestone CD, Klein JO. Otitis Media in Infants and Children. Philadelphia: Saunders (1988)
52. Ingelstedt S, Ivarsson A, Jonson B. Quantitative determination of tubal ventilation during changes in ambient pressure as during ascent and descent in aviation. Acta Otolaryngol (1967) 228(Suppl):31.

53. Hergils L, Magnuson B. Regulation of negative middle ear pressure without tubal opening. Arch Otolaryngol Head Neck Surg (1988) 114(12):1442-4. doi:10.1001/archotol.1988.01860240092030

54. Politzer A. Diseases of the Ear. 4th ed. Philadelphia: Lea Brothers \& Co (1903).

55. Shupak A, Attias J, Aviva J, Melamed Y. Oxygen diving-induced middle ear under-aeration. Acta Otolaryngol (1995) 115(3):422-6. doi:10.3109/ 00016489509139341

56. Beuerlein M, Nelson RN, Welling DB. Inner and middle ear hyperbaric oxygen-induced barotrauma. Laryngoscope (1997) 107(10):1350-6. doi:10. 1097/00005537-199710000-00011

57. Miura MS, Mascaro M, Rosenfeld RM. Association between otitis media and gastroesophageal reflux: a systematic review. Otolaryngol Head Neck Surg (2012) 146(3):345-52. doi:10.1177/0194599811430809

58. Al-Saab F, Manoukian JJ, Al-Sabah B, Almot S, Nguyen LH, Tewfik TL, et al. Linking laryngopharyngeal reflux to otitis media with effusion: pepsinogen study of adenoid tissue and middle ear fluid. J Otolaryngol Head Neck Surg (2008) 37(4):565-71.

59. McCoul ED, Goldstein NA, Koliskor B, Weedon J, Jackson A, Goldsmith AJ. A prospective study of the effect of gastroesophageal reflux disease treatment on children with otitis media. Arch Otolaryngol Head Neck Surg (2011) 137(1):35-41. doi:10.1001/archoto.2010.222

60. Giebink GS. Otitis media: the chinchilla model. Microb Drug Resist (1999) 5(1):57-72. doi:10.1089/mdr.1999.5.57

61. Watanabe N, DeMaria TF, Lewis DM, Mogi G, Lim DJ. Experimental otitis media in chinchillas. II. Comparison of the middle ear immune responses to S pneumonia types 3 and 23. Ann Otol Rhinol Laryngol Suppl (1982) 93:9-16.

62. Giebink GS. The pathogenesis of pneumococcal otitis media in chinchillas and the efficacy of vaccination in prophylaxis. Rev Infect Dis (1981) 3(2):342-53.

63. Sadé J. The nasopharynx, Eustachian tube and otitis media. J Laryngol Otol (1994) 108(2):95-100.

64. Brook I, Shah K, Jackson W. Microbiology of healthy and diseased adenoids. Laryngoscope (2000) 110(6):994-9. doi:10.1097/00005537-200006000-00021

65. Yang YP, Loosmore SM, Underdown BJ, Klein MH. Nasopharyngeal colonization with nontypeable Haemophilus influenzae in chinchillas. Infect Immun (1998) 66(5):1973-80.

66. Syrjanen RK. The value of nasopharyngeal culture in predicting the etiology of acute otitis media in children less than two years of age. Pediatr Infect Dis J (2006) 25(11):1032-6. doi:10.1097/01.inf.0000241097.37428.1d

67. Brook I, Gober AE. In vitro bacterial interference in the nasopharynx of otitis media-prone and non-otitis media prone children. Arch Otolaryngol Head Neck Surg (2000) 126(8):1011-3. doi:10.1001/archotol.126.8.1011

68. Hall-Stoodley L, Stoodley P. Evolving concepts in biofilm infections. Cell Microbiol (2009) 11(7):1034-43. doi:10.1111/j.1462-5822.2009.01323.x

69. Fux CA, Costerton JW, Stewart PS, Stoodley P. Survival strategies of infectious biofilms. Trends Microbiol (2005) 13(1):34-40. doi:10.1016/j.tim.2004.11.010

70. Stewart PS, Costerton JW. Antibiotic resistance of bacteria in biofilms. Lancet (2001) 358(9276):135-8. doi:10.1016/S0140-6736(01)05321-1

71. Mah TF, O'Toole GA. Mechanisms of biofilm resistance to antimicrobial agents. Trends Microbiol (2001) 9(1):34-9. doi:10.1016/S0966-842X(00)01913-2

72. Potera C. Forging a link between biofilms and disease. Science (1999) 283(5409):1837. doi:10.1126/science.283.5409.1837

73. Zuliani G, Carron M, Gurrola J, Coleman C, Haupert M, Berk R, et al. Identification of adenoid biofilms in chronic rhinosinusitis. Int J Pediatr Otorhinolaryngol (2006) 70(9):1613-7. doi:10.1016/j.ijporl.2006.05.002

74. Bakaletz LO. Bacterial biofilms in otitis media: evidence and relevance. Pediatr Infect Dis J (2007) 26(10 Suppl):S17-9. doi:10.1097/INF.0b013e318154b273

75. Post JC. Direct evidence of bacterial biofilms in otitis media. Laryngoscope (2001) 111(12):2083-94. doi:10.1097/00005537-200112000-00001

76. Ehrlich GD, Veeh R, Wang X, Costerton JW, Hayes JD, Hu FZ, et al. Mucosal biofilm formation on middle-ear mucosa in the chinchilla model of otitis media. JAMA (2002) 287(13):1710-5. doi:10.1001/jama.287.13.1710

77. Hall-Stoodley L, Hu FZ, Gieseke A, Nistico L, Nguyen D, Hayes J, et al. Direct detection of bacterial biofilms on the middle-ear mucosa of children with chronic otitis media. JAMA (2006) 296(2):202-11. doi:10.1001/jama.296.2.202 
78. Thornton PB, Rigby P, Wiertsema SP, Filion P, Langlands J, Coates HL, et al. Multi-species bacterial biofilm and intracellular infection in otitis media. BMC Pediatr (2011) 11:94. doi:10.1186/1471-2431-11-94

79. Barakate M, Beckenham E, Curotta J, da Cruz M. Bacterial biofilm adherence to middle-ear ventilation tubes: scanning electron micrograph images and literature review. J Laryngol Otol (2007) 121(10):993-7.

80. Hoa M, Syamal M, Sachdeva L, Berk R, Coticchia J. Demonstration of nasopharyngeal and middle ear mucosal biofilms in an animal model of acute otitis media. Ann Otol Rhinol Laryngol (2009) 118(4):292-8.

81. Zuliani G, Carlisle M, Duberstein A, Haupert M, Syamal M, Berk R, et al. Biofilm density in the pediatric nasopharynx: recurrent acute otitis media versus obstructive sleep apnea. Ann Otol Rhinol Laryngol (2009) 118(7): 519-24.

82. Hoa M, Syamal M, Schaeffer MA, Sachdeva L, Berk R, Coticchia J. Biofilms and chronic otitis media: an initial exploration into the role of biofilms in the pathogenesis of chronic otitis media. Am J Otolaryngol (2010) 31(4):241-5. doi:10.1016/j.amjoto.2009.02.015

83. Nistico L, Kreft R, Gieseke A, Coticchia JM, Burrows A, Khampang P, et al. Adenoid reservoir for pathogenic biofilm bacteria. J Clin Microbiol (2011) 49(4):1411-20. doi:10.1128/JCM.00756-10

84. Costerton JW, Nickel JC, Ladd TI. Suitable methods for the comparative study of free-living and surface-associated bacterial populations. In: Poindexter JS, Leadbetter ER, editors. Methods and Special Applications in Bacterial Ecology. New York: Plenum (1986). 3 p.

85. Costerton JW, Lewandowski Z, Caldwell DE, Korber DR, Lappin-Scott HM. Microbial films. Annu Rev Microbiol (1995) 49:711-45. doi:10.1146/annurev. mi.49.100195.003431

86. Duberstein A, Hoa M, Christensen L, Berk RS, Coticchia JM. Comparison of middle ear pathogens in nasopharyngeal biofilms and middle ear effusions of children with recurrent acute otitis media. Poster Session Presented at Combined Otolaryngological Spring Meetings. Orlando, FL: (2008).

87. Bakaletz LO. Bacterial biofilms in the upper airway - evidence for role in pathology and implications for treatment of otitis media. Paediatr Respir Rev (2012) 13(3):154-9. doi:10.1016/j.prrv.2012.03.001

88. Huang D, Swanson EA, Lin CP, Schuman JS, Stinson WG, Chang W, et al. Optical coherence tomography. Science (1991) 254(5035):1178-81. doi:10.1126/ science. 1957169

89. Dörr J, Wernecke KD, Bock M, Gaede G, Wuerfel JT, Pfueller CF, et al. Association of retinal and macular damage with brain atrophy in multiple sclerosis. PLoS One (2011) 6(4):e18132. doi:10.1371/journal.pone.0018132

90. Keane PA, Patel PJ, Liakopolous S, Heussen FM, Sadda SR, Tufail A. Evaluation of age-related macular degeneration with optical coherence tomography. Surv Ophthalmol (2012) 57(5):389-414. doi:10.1016/j.survophthal.2012.01.006

91. Zysk AM, Nguyen FT, Oldenburg AL, Marks DL, Boppart SA. Optical coherence tomography: a review of clinical development from bench to bedside. J Biomed Opt (2007) 12(5):051403. doi:10.1117/1.2793736

92. Nguyen CT, Jung W, Kim J, Chaney EJ, Novak M, Stewart CN, et al. Noninvasive in vivo optical detection of biofilm in the human middle ear. Proc Natl Acad Sci U S A (2012) 109(24):9529-34. doi:10.1073/pnas.1201592109

93. Nguyen CT, Robinson SR, Jung W, Novak MA, Boppart SA, Allen JB. Investigation of bacterial biofilm in the human middle ear using optical coherence tomography and acoustic measurements. Hear Res (2013) 301:193-200. doi:10.1016/j.heares.2013.04.001

94. Thormann KM, Saville RM, Shukla S, Spormann AM. Induction of rapid detachment in Shewanella oneidensis MR-1 biofilms. J Bacteriol (2005) 187(3):1014-21. doi:10.1128/JB.187.3.1014-1021.2005

95. Saidi IS, Biedlingmaier JF, Whelan P. In vivo resistance to bacterial biofilm formation on tympanostomy tubes as a function of tube material. Otolaryngol Head Neck Surg (1999) 120(5):621-7. doi:10.1053/hn.1999.v120.a94162

96. Jang $\mathrm{CH}$, Cho YB, Choi CH. Effect of ion-bombarded silicone tympanostomy tube on ciprofloxacin-resistant Pseudomonas aeruginosa biofilm formation. Int J Pediatr Otorhinolaryngol (2012) 76(10):1471-3. doi:10.1016/j.ijporl.2012. 06.025

97. Jang $\mathrm{CH}$, Park $\mathrm{H}$, Cho YB, Choi $\mathrm{CH}$. Effect of vancomycin-coated tympanostomy tubes on methicillin-resistant Staphylococcus aureus biofilm formation: in vitro study. J Laryngol Otol (2010) 124(6):594-8. doi:10.1017/ S0022215109992672

98. Ojano-Dirain CP, Silva RC, Antonelli PJ. Biofilm formation on coated silicone tympanostomy tubes. Int J Pediatr Otorhinolaryngol (2013) 77(2):223-7. doi:10.1016/j.ijporl.2012.10.027

99. Jang CH, Park H, Cho YB, Choi CH, Park IY. The use of piperacillin-tazobactam coated tympanostomy tubes against ciprofloxacin-resistant Pseudomonas biofilm formation: an in vitro study. Int J Pediatr Otorhinolaryngol (2009) 73(2):295-9. doi:10.1016/j.ijporl.2008.10.020

100. Chole RA, Hubbell RN. Antimicrobial activity of silastic tympanostomy tubes impregnated with silver oxide. Arch Otolaryngol Head Neck Surg (1995) 121(5):562-5. doi:10.1001/archotol.1995.01890050054010

101. Oxley KS, Thomas JG, Ramadan HH. Effect of ototopical medications on tympanostomy tube biofilms. Laryngoscope (2007) 117(10):1819-24. doi:10.1097/ MLG.0b013e3180d09ede

102. Smith A, Buchinsky FJ, Post JC. Eradicating chronic ear, nose, and throat infections: a systematically conducted literature review of advances in biofilm treatment. Otolaryngol Head Neck Surg (2011) 144(3):338-47. doi:10.1177/ 0194599810391620

103. Krespi YP, Stoodley P, Hall-Stoodley L. Laser disruption of biofilm. Laryngoscope (2008) 118(7):1168-73. doi:10.1097/MLG.0b013e31816ed59d

104. Smith AW. Biofilms and antibiotic therapy: is there a role for combating bacterial resistance by the use of novel drug delivery systems? Adv Drug Deliv Rev (2005) 57(10):1539-50. doi:10.1016/j.addr.2005.04.007

105. Vlastarakos PV, Nikolopoulos TP, Maragoudakis P, Tzagaroulakis A, Ferekidis E. Biofilms in ear, nose, and throat infections: how important are they? Laryngoscope (2007) 117(4):668-73. doi:10.1097/MLG.0b013e318030e422

106. Jones MN, Song YH, Kaszuba M, Reboiras MD. The interaction of phospholipid liposomes with bacteria and their use in the delivery of bactericides. JDrug Target (1997) 5(1):25-34. doi:10.3109/10611869708995855

107. Whitchurch CB, Tolker-Nielsen T, Ragas PC, Mattick JS. Extracellular DNA required for bacterial biofilm formation. Science (2002) 295(5559):1487. doi:10.1126/science.295.5559.1487

108. Hall-Stoodley L, Nistico L, Sambanthamoorthy K, Dice B, Nguyen D, Mershon WJ, et al. Characterization of biofilm matrix, degradation by DNase treatment and evidence of capsule downregulation in Streptococcus pneumoniae clinical isolates. BMC Microbiol (2008) 8:173. doi:10.1186/1471-2180-8-173

109. Lamppa JW, Griswold KE. Alginate lyase exhibits catalysis-independent biofilm dispersion and antibiotic synergy. Antimicrob Agents Chemother (2013) 57(1):137-45. doi:10.1128/AAC.01789-12

110. Dusane DH, Damare SR, Nancharaiah YV, Ramaiah N, Venugopalan VP, Kumar $\mathrm{AR}$, et al. Disruption of microbial biofilms by an extracellular protein isolated from epibiotic tropical marine strain of Bacillus licheniformis. PLoS One (2013) 8(5):e64501. doi:10.1371/journal.pone.0064501

111. Park H, Jang CH, Cho YB, Choi CH. Antibacterial effect of tea-tree oil on methicillin-resistant Staphylococcus aureus biofilm formation of the tympanostomy tube: an in vitro study. In vivo (2007) 21(6):1027-30.

Conflict of Interest Statement: The authors declare that the research was conducted in the absence of any commercial or financial relationships that could be construed as a potential conflict of interest.

Received: 27 August 2013; accepted: 12 December 2013; published online: 23 December 2013.

Citation: Coticchia JM, Chen M, Sachdeva L and Mutchnick S (2013) New paradigms in the pathogenesis of otitis media in children. Front. Pediatr. 1:52. doi: 10.3389/fped.2013.00052

This article was submitted to Pediatric Otolaryngology, a section of the journal Frontiers in Pediatrics.

Copyright (C) 2013 Coticchia, Chen, Sachdeva and Mutchnick. This is an open-access article distributed under the terms of the Creative Commons Attribution License (CC $B Y)$. The use, distribution or reproduction in other forums is permitted, provided the original author(s) or licensor are credited and that the original publication in this journal is cited, in accordance with accepted academic practice. No use, distribution or reproduction is permitted which does not comply with these terms. 